\title{
RITUXIMABIN REFRACTORY HIV-ASSOCIATED SPORADIC LATE-ONSET NEMALINE MYOPATHY: A CASE REPORT
}

\author{
Jucier Gonçalves Júnior ${ }^{1, \star}$, Fernando Henrique Carlos de Souza ${ }^{1}$, Renata Miossi ${ }^{1}$, Samuel Katsuyuki Shinjo ${ }^{1}$ \\ 1.Universidade de São Paulo, São Paulo (SP), Brazil. \\ *Corresponding author: juciergjunior@hotmail.com
}

\section{BACKGROUND}

Sporadic late-onset nemaline myopathy (SLONM) is a rare, late-onset muscle disorder characterized by the presence of nemaline rods in muscle fibers. It can be associated with HIV infection. Treatments based on human immunoglobulin and immunosuppressive drugs (leflunomide, thalidomide, azathioprine or mycophenolate) have been proposed. For refractory cases, the use of autologous hematopoietic stem cell transplantation has been discussed; however, literature reports anecdotal evidence of the use of rituximab as an alternative in refractory cases. Therefore, the objective was to report a case of refractory HIV-SLONM with good response to rituximab.

\section{CASE REPORT}

A 37-year-old black female with a history of HIV and an undetectable viral load with regular use of dolutegravir, darunavir, and ritonavir. Six years ago, the patient started to present objective muscle weakness in all four limbs, in addition to increased muscle enzymes and electroneuromyography with evidence of a myopathic pattern. With the initial hypothesis of polymyositis, the patient received glucocorticoid with partial improvement of clinical and laboratory status. The patient was admitted to our service for a clinical reassessment and follow-up 3 years ago. The patient had an undetectable viral load, normal protein electrophoresis, and serum levels of creatine phosphokinase oscillating at $2550 \mathrm{U} / \mathrm{L}$ using methotrexate $25 \mathrm{mg} /$ week and prednisone $5 \mathrm{mg} /$ day. She had weakness in the scapular and pelvic girdle, required a wheelchair for locomotion, and showed muscle magnetic resonance with evidence of symmetrical and bilateral muscle edema in the muscular bellies of the pelvic girdle and thighs. A muscle biopsy showed a myopathic and dystrophic patterns with the presence of marginal vacuoles with nemaline rods. Regarding the possibility of HIV-SLONM, methylprednisolone pulse therapy $3 \mathrm{~g}$ was started in one dose and immunosuppressive drugs of previous use were maintained without significant improvement; therefore, opted for rituximab ( $2 \mathrm{~g} / \mathrm{cycle}$, semester) was introduced. The patient had a progressive improvement and, after two rituximab cycles, there was an important improvement in muscle weakness and independence for basic activities of daily living and a drop in creatine phosphokinase (375 U/L).

\section{CONCLUSION}

The present case suggests that rituximab may be a promising biological treatment for refractory cases of HIV-SLONM.

\section{KEYWORDS}

Case Report, HIV, Nemaline myopathy, Rituximab. 